\title{
Epidural Hematoma: Vigilance beyond Guidelines
}

\author{
Nitin Madhukar Bhorkar, Tasneem Saleh Dhansura, Urmila Bhaktiprasad Tarawade, Sanket Sharad Mehta \\ Department of Anaesthesiology and Surgical Oncology, Saifee Hospital, Mumbai, Maharashtra, India
}

\section{Abstract}

Coagulopathy either from the use of anticoagulant, antiplatelet, or thrombolytic medications or from underlying medical conditions is considered one of the major risk factors for epidural hematoma formation related to epidural catheter placement or removal. The American Society of Regional Anesthesia and Pain Medicine (ASRA) has laid down guidelines regarding timing of neuraxial blockade or removal of neuraxial catheters in patients receiving either antithrombotic or thrombolytic therapy. We present a case of acute onset of paraplegia because of an epidural hematoma following removal of the epidural catheter in a patient who was given the first dose of antithrombotic therapy after the removal of the epidural catheter as per the ASRA guidelines. The epidural hematoma was diagnosed with an urgent magnetic resonance imaging, and the patient was urgently taken up for surgical evacuation of the hematoma. The patient made full recovery over 1 week period.

Keywords: Anticoagulation, epidural catheter, epidural hematoma

\section{INTRODUCTION}

A combination of anticoagulation and epidural catheter has always been a problematic issue. ${ }^{[1]}$ The times of insertion and removal of epidural catheters are high-risk periods for epidural hematoma formation which is a rare but recognized complication. ${ }^{[2]}$ The incidence of epidural hematoma in the setting of epidural catheter placement or removal is reported to be as low as one in $1,50,000 \cdot{ }^{[3]}$ We report a case of paraplegia that developed after removal of a thoracic epidural catheter followed by low molecular weight heparin (LMWH) treatment. Surgical evacuation of epidural hematoma was done following which the patient's symptoms improved gradually and the patient recovered completely.

\section{Case Report}

A 46-year-old woman (height $-160 \mathrm{~cm}$, weight $-60 \mathrm{~kg}$ ) underwent cytoreductive surgery for carcinoma of the left ovary under combined epidural and general anesthesia. Her past medical history was unremarkable, and her preoperative investigations including coagulation profile were within normal limits. Before induction of general anesthesia, an epidural catheter was inserted uneventfully at T7-T8 intervertebral level using 16G Tuohy needle. Epidural space was identified using loss of resistance to saline, with no blood seen through epidural needle and the catheter. Postoperative

\begin{tabular}{|l|l|}
\hline \multicolumn{3}{c|}{ Access this article online } \\
\hline Quick Response Code: & Website: \\
\hline & www.ijccm.org \\
\hline
\end{tabular}

analgesia was provided with continuous epidural infusion of $0.2 \%$ ropivacaine along with $2 \mathrm{mcg} / \mathrm{ml}$ of fentanyl at the rate of $5 \mathrm{ml} / \mathrm{h}$. Pneumatic calf pump was started preoperatively and continued in the postoperative period to prevent thromboembolism. On the $3^{\text {rd }}$ postoperative day, epidural catheter was removed after confirming normal coagulation parameters. For deep vein thromboprophylaxis, a single dose of fractionated heparin (dalteparin $2500 \mathrm{U}$ ) was given subcutaneously $6 \mathrm{~h}$ after the removal of epidural catheter according to the American Society of Regional Anesthesia and Pain Medicine (ASRA) guidelines.

Six hours after the first dose of dalteparin, the patient complained of severe back pain along with loss of sensory and motor power in the lower limbs. Clinical examination revealed no sensations and muscle power of grade $0 / 5$ in both the lower limbs.

With high index of suspicion of spinal/epidural hematoma causing spinal cord compression, the patient was started on intravenous methylprednisolone infusion, and further dosage of dalteparin sodium was withheld.

Address for correspondence: Dr. Nitin Madhukar Bhorkar, 201, Parle Pearl CHS, G.B. Indulkar Marg, Vile Parle East, Mumbai - 400 057, Maharashtra, India. E-mail: drnmbhorkar@gmail.com

This is an open access journal, and articles are distributed under the terms of the Creative Commons Attribution-NonCommercial-ShareAlike 4.0 License, which allows others to remix, tweak, and build upon the work non-commercially, as long as appropriate credit is given and the new creations are licensed under the identical terms.

For reprints contact: reprints@medknow.com

How to cite this article: Bhorkar NM, Dhansura TS, Tarawade UB, Mehta SS. Epidural hematoma: Vigilance beyond guidelines. Indian J Crit Care Med 2018;22:555-7. 
Within $2 \mathrm{~h}$ of onset of symptoms, an urgent magnetic resonance imaging (MRI) was obtained which revealed a localized epidural hematoma posteriorly from D6 to D8 level causing compression and significant anterior displacement of adjacent spinal cord [Figure 1].

The patient was moved to the operating room directly from MRI suite for emergency laminectomy and decompression under general anesthesia. The hematoma was meticulously evacuated, and no active bleeding vessel could be identified [Figure $2 \mathrm{a}$ and $\mathrm{b}$ ].

She regained some sensory power in the lower limbs on the day of the spine surgery. On the $2^{\text {nd }}$ postoperative day, some toe movement was seen. There was a gradual improvement in muscle power over the next few days, and on the $7^{\text {th }}$ postoperative day, the patient had regained normal muscle power of both the lower limbs. Recovery was faster in the left lower limb as compared to right side.

Subsequent follow-up did not reveal any sensory-motor abnormality.

\section{Discussion}

There has been increased awareness over the last decade about thromboembolic events and has resulted in the administration of prophylactic anticoagulants as a standard of care, to those patients who are at high risk. Epidural anesthesia or analgesia is commonly used in patients undergoing major laparotomies as an adjuvant to general anesthesia and for postoperative pain relief. The time of insertion or removal of the epidural catheter is the high-risk period for the formation of epidural hematoma in patients receiving prophylactic anticoagulation therapy.

In a patient who is already on anticoagulation therapy, the hepatic, renal impairment may affect the onset and duration of action of the anticoagulant. The following abnormal coagulation parameters during the perioperative period have been identified as risk factors for epidural hematoma occurrence. ${ }^{[4]}$

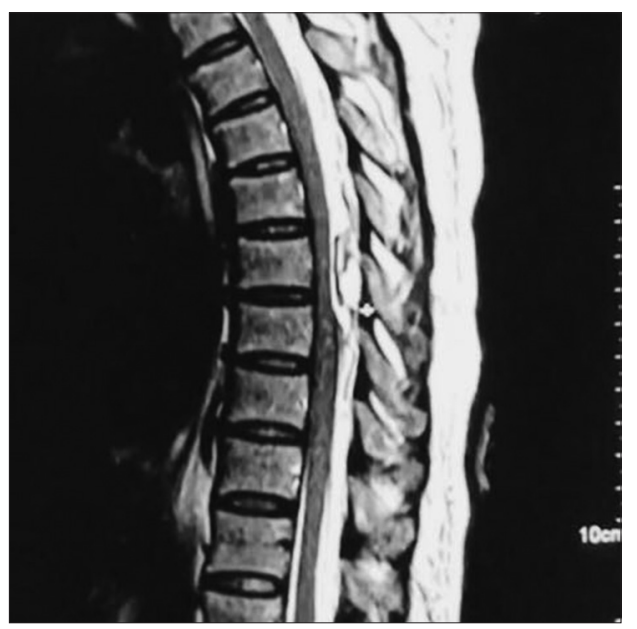

Figure 1: Epidural haematoma as seen on MRI
1. Activated partial thromboplastin time $>35 \mathrm{~s}$

2. International normalized ratio $>1.5$

3. Platelet count $<100,000$.

This patient neither fits into any of these criteria nor was on any anticoagulant therapy. The first dose of anticoagulant dalteparin was given $6 \mathrm{~h}$ after removal of the catheter, well beyond the minimum $2 \mathrm{~h}$ interval recommended in the 2010 ASRA guidelines. ${ }^{[5]}$ The latest 2018 guidelines now recommend $4 \mathrm{~h}$ interval for the first dose of anticoagulant after epidural catheter removal. If the patient is already receiving prophylactic LMWH, then the guidelines recommend removal of epidural catheter after at least $12 \mathrm{~h}$ of administration of the last dose of LMWH. ${ }^{[6]}$ The ASRA guidelines are essentially the consensus statements that represent collective experience of recognized experts in the field of neuraxial anesthesia and anticoagulation. ${ }^{[7]}$ The rarity of this complication and the absence of any mandatory data registry make it extremely difficult to formulate guidelines for exact time interval. In view of our experience, it may be advisable to extend the guideline interval keeping in mind the risk-benefit ratio of doing so and to continue close neurological monitoring of the patient.

For spine imaging, an MRI gives far superior quality of images as compared to computed tomography. However, there is always a worry about subjecting the patient with skin staples and internal vascular clips to an MRI for fear of disrupting the staples and internal clips. Most of the previous case reports have mentioned not subjecting the patient to an MRI for the same reason. However, there is some literature available which supports safety aspect of MRI in patients with staples. In an interesting study on pig feet, it was found that it was safe to use MRI in the presence of skin staples as it did not cause displacement or heating of the skin staples. ${ }^{[8]}$ Another study has also demonstrated safety of MRI of 3 Tesla or less power in the presence of skin staples and vascular occlusion clips. ${ }^{[9]}$ It is vital to confirm the exact diagnosis of a hematoma and its extent before subjecting the patient for an emergency spine surgery.

In some case reports, patients have been managed conservatively. In our case, in spite of early diagnosis and surgical intervention,
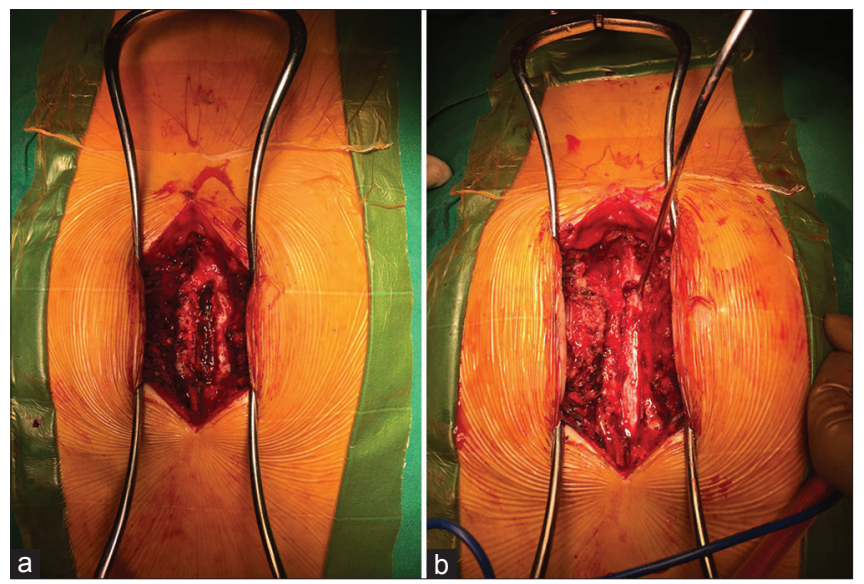

Figure 2: (a) Before evacuation, (b) After evacuation 
it took 1 week for complete neurological recovery. The best results have been seen when patients are operated within $12 \mathrm{~h}$ of onset of the symptoms. ${ }^{[10]}$ Considering this, conservative management is questionable, and the results are unpredictable.

It may be advisable to extend the ASRA guideline interval for anticoagulant dose after removal of the epidural catheter and to continue close neurological monitoring of the patient. The presence of skin staples or vascular clips should not be a deterrent for subjecting the patient to an MRI for accurate diagnosis. Early diagnosis and surgical intervention offer the best possible chance of neurological recovery.

\section{Declaration of patient consent}

The authors certify that they have obtained all appropriate patient consent forms. In the form the patient(s) has/have given his/her/their consent for his/her/their images and other clinical information to be reported in the journal. The patients understand that their names and initials will not be published and due efforts will be made to conceal their identity, but anonymity cannot be guaranteed.

\section{Financial support and sponsorship}

Nil.

\section{Conflicts of interest}

There are no conflicts of interest.

\section{RefERENCES}

1. Epidural Catheters, Anticoagulation and the risk of Spinal Hematoma: A Review of Literature. Internet J Orthoped Surg 2007;6.
2. Gulur P, Tsui B, Pathak R, Koury KM, Lee H. Retrospective analysis of the incidence of epidural haematoma in patients with epidural catheters and abnormal coagulation parameters. Br J Anaesth 2015;114:808-11.

3. Ruppen W, Derry S, McQuay H, Moore RA. Incidence of epidural hematoma, infection, and neurologic injury in obstetric patients with epidural analgesia/anesthesia. Anesthesiology 2006;105:394-9.

4. Cook TM, Counsell D, Wildsmith JA; Royal College of Anaesthetists Third National Audit Project. Major complications of central neuraxial block: Report on the Third National Audit Project of the Royal College of Anaesthetists. Br J Anaesth 2009;102:179-90.

5. Horlocker TT, Wedel DJ, Rowlingson JC, Enneking FK, Kopp SL, Benzon HT, et al. Regional anesthesia in the patient receiving antithrombotic or thrombolytic therapy: American society of regional anesthesia and pain medicine evidence-based guidelines (Third edition). Reg Anesth Pain Med 2010;35:64-101.

6. Horlocker T, Vandermeuelen E, Kopp S, Gogarten W, Leffert L, Benzon $\mathrm{H}$, et al. Regional anaesthesia in the patient receiving antithrombotic or thrombolytic therapy. Reg Anesth Pain Med 2018;43:263-309.

7. Narouze S, Benzon HT, Provenzano DA, Buvanendran A, De Andres J, Deer TR, et al. Interventional spine and pain procedures in patients on antiplatelet and anticoagulant medications: Guidelines from the American Society of Regional Anesthesia and Pain Medicine, the European Society of Regional Anaesthesia and Pain Therapy, the American Academy of Pain Medicine, the International Neuromodulation Society, the North American Neuromodulation Society, and the World Institute of Pain. Reg Anesth Pain Med 2015;40:182-212.

8. Gayton JC, Sensiba P, Imbrogno BF, Venkatarayappa I, Tsatalis J, Prayson MJ, et al. The effects of magnetic resonance imaging on surgical staples: An experimental analysis. J Trauma 2011;70:1279-81.

9. Gill A, Shellock FG. Assessment of MRI issues at 3-Tesla for metallic surgical implants: Findings applied to 61 additional skin closure staples and vessel ligation clips. J Cardiovasc Magn Reson 2012;14:3.

10. Lawton MT, Porter RW, Heiserman JE, Jacobowitz R, Sonntag VK, Dickman CA, et al. Surgical management of spinal epidural hematoma: Relationship between surgical timing and neurological outcome. J Neurosurg 1995;83:1-7. 